\title{
How Generic is I(nformation) T(echnology)?
}

\author{
Iwona Miliszewska, Anne Venables, and Grace Tan \\ Victoria University, Melbourne, Australia
}

\author{
Iwona.Miliszewska@vu.edu.au Anne.Venables@vu.edu.au \\ Grace.Tan@vu.edu.au
}

\begin{abstract}
Victoria University will introduce a generic Science Degree in 2009. Students in the degree will share a common first year and then choose a specialization, for instance biotechnology, chemistry, computing, food science, or environmental science. This paper reflects on the need for the development of enabling information technology (IT) skills among first-year students in the Degree. Many students already use IT to communicate, collaborate, work, and learn. However, they need to learn how to use technology intelligently, creatively, and ethically to accomplish intellectual pursuits; in addition, they should develop these skills at the beginning of the ir course, so as to optimize their learning throughout their studies and maximize educational outcomes. How could these skills be developed in students of a generic science degree? Are IT skills generic, too? The paper discusses the growing need for the development of advanced IT skills in science students; it shows the disparity between current university practice and the expectations of the world at large; it examines the generic nature and transferability of advanced IT skills; and, it proposes explic it incorporation of these skills into the curriculum of a generic science degree, including suggestions for effective implementation.
\end{abstract}

Keywords: IT skills, generic science degree, digital literacy, computer science.

\section{Introduction}

A curriculum revolution has started to transform the Australian higher education sector, as several leading universities embarked on radical course reforms involving a reduction of discipline-based undergraduate course offerings in favour of a much smaller number of broad undergraduate courses integrating the humanities and science; for instance, the University of Western Australia plans to cut its undergraduate courses from seventy to six by the beginning of the 2009 academic year. Upon completion of a broad undergraduate degree, students can pursue specialised graduate courses (Slattery, 2008). The reform process has strong international parallels, as individual universities such as Harvard, and entire systems such as the European universities covered by the Bologna Accord, have embraced the cause of curriculum renewal; this renewal goes to the heart of teaching, learning and graduate competencies

Material published as part of this publication, either on-line or in print, is copy righted by the Informing Science Institute. Permission to make digital or paper copy of part or all of these works for personal or classroom use is granted without fee provided that the copies are not made or distributed for profit or commercial advantage AND that copies 1) bear this notice in full and 2) give the full citation on the first page. It is permissible to abstract these works so long as credit is given. To copy in all other cases or to republish or to post on a server or to redistribute to lists requires specific permission and payment of a fee. Contact Publisher@InformingScience.org to request redistribution permission.

Victoria University has introduced a similar curriculum reform, albeit on a smaller scale. Beginning in semester $1 / 2009$, it will offer a generic Science Degree, replacing a number of current specialist degrees. However, the generic Degree will be "generic" only up to a point that is, it will include a common first year and branch out into Degree 
specialisations in the second and third year; the specialisations will include Biotechnology, Chemistry, Food Science, Computing, Ecology, Community Science and others. The first year of the Degree will be rich in disciplinary breadth across the broad areas of the sciences, and in the second and third year intense disc iplinary depth and/or professional expertise will be gained.

The composition of the first year was subject to much debate, as representatives of the various specialisations fought to convince the program committee that theirs was an area of general interest and importance and therefore should be studied by all students. The arguments put forward by the computing experts were particularly compelling. Given that IT, or indeed computer science, underpins many of the scientific disciplines, it was only fitting that the development of computing skills should apply to all science students and that it should start in the first year of the Degree. This decision was supported by Microsoft Research Cambridge's report "Towards 2020 Science" (Microsoft Research, 2005). This report was the result of a workshop that invited an international group of natural and computer scientists to put together a roadmap for science, and particularly computing, over the next sixteen years before 2020 . The central tenet was that computer science would transform science in two ways: as a tool for doing "traditional" science, and as a technique for performing experiments and creating models. Thus, the study has strongly identified the importance of mathematical, quantitative and computational and indeed IT skills to all students in science. It concluded that 'Scientists will need to be completely computationally and mathematically literate, and by 2020 , it will simply not be possible to do science without such literacy' (Microsoft Research, 2005, p. 8).

While information literacy skills have been recognised in most science course curricula, more advanced IT skills and digital literacy have been largely overlooked; yet, they are all-

encompassing with applications that permeate various disciplines of science (Miliszewska, 2008). Thus IT should be regarded as a powerful facilitator to higher-level learning. How should this advanced IT literacy be developed? How can its relevance be maintained in a generic Degree? Is such literacy generic? The following sections discuss these issues and propose suggestions for introducing essential tools and technologies for tomorrow's scientists.

\section{The Need for IT Skills in Science Students}

Today's members of the skilled workforce are expected to display a broad range of generic skills including good communication and team working abilities, strong problem-solving and numeric proficiency and, most particularly, expertise in information technology. In their extensive research of British workplaces, Dickerson and Green (2004) assessed the utilization and relative importance of a broad range of generic skills and capabilities including: computing skills, literacy, numeracy, technical know-how, high-level communication skills, planning skills, client communication skills, horizontal communication skills, problem-solving, and checking skills. They found computer skills and high-level communications skills to be the most valued capabilities and both of them carried positive wage premiums. Further, Dolton and Pelkonen (2007) estimated the pay differential for computer literate workers to be between $3-10 \%$ with word-processing, email and programming skills returning the highest rewards.

As industry has become increasingly more information and communications technology (ICT) intensive, there has been vast growth in computer skills utilization in the workplace. Dickerson and Green (2004) noted that, from 1997 onwards, the use of computers in the workplace has become more sophisticated over time. Importantly, Kirby \& Riley (2006) reported on a shift to value more highly the ICT skills acquired from schooling and work experience over those ICT skills that have been learnt on the job. This underlines the pivotal role of universities in ensuring that all graduates are equipped with a strong set of IT capabilities as well as discipline specific knowledge to be work ready. 
Worldwide there has been a growing trend for universities to publicly state the skills and attributes that their emerging graduates are expected to possess, although the approaches to the acquisition of graduate attributes through undergraduate programs differs from country to country (Treleaven \& Voola, 2008). Additionally, publicly funded institutions in Australia are expected to articulate the perceived benefits of their respective courses and report annually to government upon the means through which they promote the development of these generic capabilities amongst their exiting students (Toleman, Roberts, \& Ryan, 2004). For example, the Graduate Capabilities (GCs) Policy at Victoria University ensures statutory requirements are met through specifying a framework for all courses in which to embed the development of core graduate attributes. According to the policy, in addition to the ir technical and field of study-specif ic knowledge and skills, a Victoria University graduate is able to:

1. problem solve in a range of settings;

2. locate, critically evaluate, and use written, numerical and electronic information;

3. communicate in a variety of contexts and modes;

4. work both autonomously and collaboratively;

5. work in an environmentally, socially and culturally responsible manner; and

6. manage learning and career development opportunities.

The policy emphasizes to academics the importance the University places upon the incremental development of graduate capabilities in all its programs and its implementation is intended to enhance the employability of its students and develop the ir effectiveness as lifelong learners (Victoria University, 2008).

Each of the above capabilities is to be developed at each year level of a course, and the students' graduate skills are to be developed progressively over time. Thus, they should begin with less demanding and more familiar tasks in the first year of their studies and, in second and third year, proceed with more complex tasks further removed from their original experiences. This process should facilitate students' transition from novice undergraduates to professionals. Although the core graduate capabilities have been defined as generic, they are context dependent. Consequently, their integration into the curriculum will vary between disciplines and courses. In addition, the University adopted a context-specific curriculum integration approach to the development of the graduate capabilities in preference to stand-alone modules specifically designed to develop those capabilities. Hence, the development of the GCs is to be embedded in the discipline know ledge and skills. It was recommended that all curricula involving GCs make explicit the connections between the attributes developed in the course and requirements for these attributes in the workplace.

While the list of desirable graduate capabilities included in the GC policy is quite comprehens ive, it does not include any explicit reference to the acquisition and development of IT skills - an issue discussed by Miliszewska (2008) in relation to an earlier iteration of the University's Core Graduate Attributes Policy. Are IT capabilities absent from the policy because the need for the development of IT skills in this day and age is so obvious that it need not be explicated? Or, are IT skills not suffic iently generic to be regarded as a common graduate capability? The following section argues that IT skills, indeed, re late to, and underpin, all the other capabilities identified in the policy and outlines a plan for the development of contextualized generic IT skills in students of a Science Degree.

\section{Embedding IT Skills in a Generic Degree}

The new initiative to develop a Generic Science Degree at Victoria University with common first year units and specializations in the second and third year units will allow students with an 
interest in science to experience science in general before committing themselves to a particular specialization. The common first year of the program is built upon a broad set of units of study including chemistry, biomedical sciences, environmental science, food technology, information technology, and physics. These units aim to provide students with the necessary foundation know ledge and generic skills to enable them further studies in the specialization of choice in the second and third year of study.

The development of the Degree at Victoria incorporated, of course, the GC policy. As specified by the policy, the Degree promotes a step-by-step development of all graduate capabilities over the three-year duration. In particular, introductory development of generic skills is expected to take place in the common first year, where collectively, the broad spectrum of units provides suitable coverage of each graduate capability. For instance, the Global Environmental Issues unit is designed to promote social and cultural appreciation and an environmental awareness in students as they progress through the ir studies, whereas, units in Mathematics and Statistics emphasize the development of problem solving and numeracy skills.

Likewise, over the duration of the ir degree, students will need to develop a range of information technology and digital skills to model and solve problems in the ir respective specializations.

Whilst integrating information from various software sources, students will need to gain competence in a range of software tools such as spreadsheets, database management systems, internet search engines, and discipline specific software. Through these experiences, students will enhance their understanding of the importance and application of computing in science and develop an ability to identify, discuss and appreciate social, ethical, and intellectual property issues arising from the use of information technology in our society.

Given the broad spectrum of disciplines in the generic Science Degree, what is the most appropriate pedagogy to ensure that all students develop suitable IT skills and digital literacy for their respective specializations? Should each specialization be solely respons ible for developing the digital literacy capability of its cohort? And if so, should the content be confined to discipline specific IT units or disseminated amongst the specialization units? Most importantly, some computing skills like information database searching for instance are broadly applicable (generic) across cohorts in all specializations; should such skills be developed independently by each specialization?

A survey of academics representing the various specialization streams within the generic degree detailed a set of computing competencies needed by their graduates. Some of these competencies, such as database searching, were identified as very important by the majority of the disciplines, thus, deeming these skills generic (applicable to the various disciplines). Consequently, after much deliberation, it was decided to house the development of IT skills in a dedicated enabling IT unit to be completed by all students in the first year of the Science Degree. The unit will focus on the development of the relevant IT skills in conjuction with, and in support of, each of the graduate capabilities identified by the Victoria University GC Policy; this will be achieved through the effective use of software tools and communication media to model and solve problems, critically evaluate information and communicate professionally, work collaboratively, and to relate studies to future professional careers. The unit will develop overall sound generic IT skills with a particularly strong focus on developing graduate capability to locate, critically evaluate, and use written, numerical and electronic information (graduate capability number two). The primary mandate of the proposed core generic IT unit will be to complement the development of generic IT skills with a practical application of those skills in the various areas of students' future specializations. 


\section{The Conceptual Framework for the Enabling IT Unit}

The template for the development of compulsory quantitative skills and IT skills in commencing science students is currently under development. It is intended that the compuls ory first-year IT unit would aim to introduce students to the basic concepts, tools, skills and competencies required of all scientists; content will include computer science, information technology, information management and communication. Drawing on the literature and reported examples of good practice, it was decided that the material would be covered in a contextualized manner, drawing heavily on interesting and relevant examples from areas such as biology, chemistry, earth sciences and physics.

The unit will be delivered via a mixture of lectures, workshops, fie ldwork, competency-based modules and inquiry-based projects. Students will be exposed to the applications of these conceptual and technological tools to a wide range of scientific areas, drawing on big issues in science, and integrated with topics encountered in other first-year science units. Students will develop their analytical, problem solving, and report writing skills and will be exposed to issues of professionalism such as ethics (including cyber ethics).

Through this enabling unit, students will master a range of computing skills needed to work with spreadsheets, database management systems, and internet search engines just to name a few; at the same time, they will re late those skills to various specializations within the Degree. Particularly, students will be taught how to find, research and evaluate electronically available discipline-specific material using appropriate search engines and databases. In their data management tasks, students will come to recognize and learn how to manipulate different file formats, while maintaining awareness of document security, transfer, and version control. Then, using various statistical packages to analyze and interpret data, students will proceed with the development of effective presentations and demonstrations for their own disciplines by using appropriate software packages and communication media. Students will be involved in practical tasks including authoring websites and building small-scale applications for managing information; they will have an opportunity to select a discipline-specific focus for the tasks and thus appreciate the many social, ethical, and intellectual property issues arising from the widespread use of information technology in the ir area of specialization.

For example, all students will learn how to use and operate spreadsheets but, students in the chemistry specialization will engage in practical tasks involving data related to the chemical composition of materials. Ecology students on the other hand will work with data related to a nature reserve (animal population of the nearby wetlands) and the community science students will analyze and present data related to the University community centre.

Students will need to learn also how to search for factual information in a variety of databases. Here the practical tasks for the ecology students will involve locating and accessing government databases on flora and fauna, creating their own data tables and populating them with the data extracted from the searched databases, and importing the table results to Google Earth to visually represent the findings. The corresponding practical tasks for the chemistry students will involve search engines such as eMolecules or ChemSpider to search, aggregate and data mine publicly available chemical information from database such as PubChem (Van Noordern, 2007). Furthermore, students will author their own website which will address a topical issue within their discipline. For instance in food science, a suitable website might address the issue of genetically modified foods. Then throughout the unit, students will progressively update their websites with information and materials which they have researched and organised in the enabling IT unit. 


\section{Conclusions}

The inclusion of a core computing unit in the first year of a generic Science Degree at Victoria University has provided an opportunity to address a growing need for the development of adequate IT skills in University students, and particularly in science students. Information technology has been transforming various disciplines of life sciences and physical sciences as a tool (for "doing" science) and a technique (for conducting experiments and creating models). This evolution in the application of IT in science demands that science students be equipped $w$ ith appropriate IT skills and that the development of these skills should begin as early as possible in the course of their science studies. The development of such skills in students is a challenging task, especially in the context of a generic Degree, where students enroll in the main specialization of their choice, but they all share a common first year.

An enabling computing unit that is being developed in response to this challenge has drawn on the generic nature of IT skills and the very philosophy underpinning the generic Degree; indeed, the computing unit mimics the structure of the Degree. Like the first-year units, which are common for all specializations of the Degree, the theoretical component of the computing unit will be common for all specializations. And, just as the subsequent specialization streams of the Degree focus on their particular discipline areas, the practical component of the computing unit will include a number of specialization-specific versions. Thus, the framework for the delivery of the IT unit further reinforces the generic character of the Science Degree and, at the same time, demonstrates that information technology skills are, indeed, generic.

\section{References}

Dickerson, A., \& Green, F. (2004). The growth and valuation of computing and other generic skills. Oxford Economic Papers, 56, 374-406.

Dolton, P., \& Pelkonen, P. (2007). The impact of computer use, computer skills and computer use intensity: Evidence from WERS 2004. Retrieved October, 2008 fro $\mathrm{m}$ http://cee.lse.ac.uk/cee\%20dps/ceedp81.pdf

Kirby, S., \& Riley, R. (2006). The returns to general versus job-specific skills: The role of information and communication technology. Discussion Paper 274, National Institute of Economic and Social Research. Retrieved October, 2008 from www.niesr.ac.uk/pubs/dps/dp274.pdf

Microsoft Research. (2005). Towards 2020 science. Research Report 2005. Retrieved October, 2008 from http://research.micros oft.com/towards2020science/downloads.htm

Milis ze wska, I. (2008). ICT skills: An essential graduate skill in today's global economy? Journal of Issues in Informing Science and Information Technology, 5, 101-109. Retrieved from http://proceedings.informingscience.org/InSITE2008/InSITE08p 101-109Milis438.pdf

Slattery, L. (2008, September 24). Courses trim for g lobal outlook. The Australian. Retrieved March 2009 from $\mathrm{http}: / /$ www.theaustralian.news.com.au/story/0,25197,24392390-12332,00.ht ml

Toleman, M., Roberts, D., \& Ryan, C. (2004). Retrofitting generic graduate attributes: A case-study of information systems undergraduate programs. Journal of Issues of Informing Science and Information Technology, 1, 625-635. Retrieved from http://articles.iisit.org/088tolem.pdf

Treleaven, L., \& Voola, R. ( 2008). Integrating the development of graduate attributes through constructive align ment. Journal of Marketing Education, 30, 160-174.

Van Noordern, R. (2007). Surfing Web2.0. Retrieved October, 2008 from http://www.rsc.org/chemistryworld/Is sues/2007/Dece mber/SurfingWeb20.asp

Victoria University. (2008). VU graduate capabilities. Internal University policy document. 


\section{Biographies}

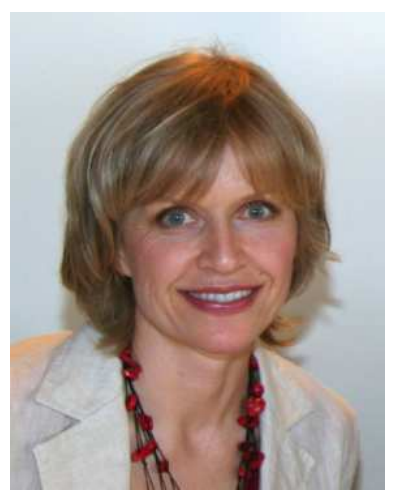

Dr Iwona Milisze wska is a senior lecturer in computer science at Victoria University, Melbourne, Australia. She has led and participated in research projects involving transnational education, effective teaching methods, life long learning and women in computer science, and has published in these areas. Currently, Iwona is leading a grant-funded research project aimed at the development and implementation of an enabling computing unit for a new generic Science Degree.

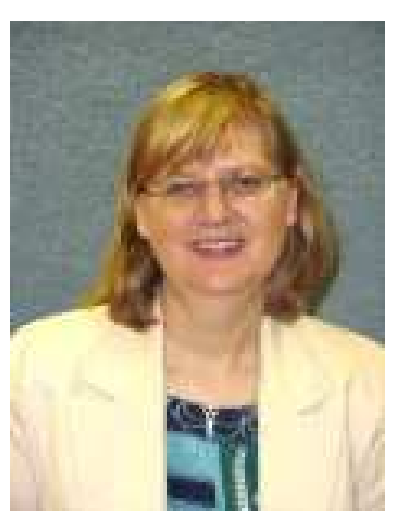

Anne Venables lectures in Computer Science and Information Technology at Victoria University, Melbourne, Australia. She has research and teaching interests in innovations in computing education and the application of intelligent systems in biological systems. Together with her colleagues Iwona Miliszewska and Grace Tan, Anne is assisting on a research project to develop and implement an enabling computing unit for the new generic Science Degree.

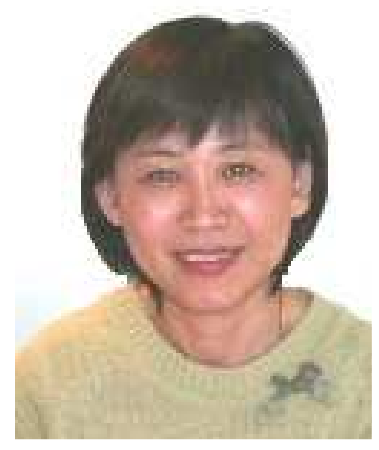

Grace Tan is a senior lecturer in Computer Science at Victoria University, Melbourne, Australia. Her research interests include investigations of innovative teaching methods, the development of graduate attributes, and issues related to female students in computing courses and Grace has published in these areas. Grace, together with her colleagues Iwona Miliszewska and Anne Venables, is assisting on a research project to develop and implement an enabling computing unit for the new generic Science Degree. 